\title{
PHYTOHORMONE INDUCED CHANGES ON BONE HISTOLOGY IN NORMAL AND DIABETIC MALE RAT
}

\author{
VELAN ATHITHAN ${ }^{1}$, KOTTEAZETH SRIKUMAR ${ }^{1 *}$ \\ 1Department of Biochemistry and Molecular Biology, School of Life Sciences, Pondicherry University, Pondicherry 605014, India \\ Email: ketoathi@gmail.com
}

Received: 19 Oct 2016 Revised and Accepted: 29 Dec 2016

\section{ABSTRACT}

Objective: To study the effect of brasslinolide keto isoform 28-homocastasterone in diabetic male rat bone marrow cells, bone histological changes, electrolytes and alkaline phosphatase activity in rat blood.

Methods: Diabetes was induced in the group $(\mathrm{n}=6)$ of rats with a single peritoneal injection of streptozotocin $(60 \mathrm{mg} / \mathrm{kg}$ bwt). With a treatment schedule of 15 consecutive days, control $(n=6)$ and diabetic rats received $666 \mu \mathrm{g} / \mathrm{kg}$ bwt of 28 -homocastasterone. Circulating blood cell count, cell indices, bone marrow cells, bone histology, electrolytes $\mathrm{Na}^{+}, \mathrm{K}^{+}, \mathrm{Cl}-\mathrm{P}, \mathrm{Ca}^{2+}$ and alkaline phosphatase activity was assessed.

Results: Cytological examination showed an increased erythrocyte progenitor and megakaryocyte cell lineage along with improved osteoblastic and bone histomorphology in the treated group was noted. A significant reduction in electrolytes level $(p<0.05)$ and increased in alkaline phosphatase activity $(\mathrm{p}<0.05)$ was noted in treated groups.

Conclusion: It is suggested that brassinosteroid keto isoform 28-homocastasterone exhibits a hematopoietic effect in diabetic rat and improves bone histology while reducing hyperglycemic damage in bone.

Keywords: Phytohormone, 28-homocastasterone, Diabetic, Bone, Osteoblast

(C) 2016 The Authors. Published by Innovare Academic Sciences Pvt Ltd. This is an open access article under the CC BY license (http://creativecommons.org/licenses/by/4. 0/) DOI: http://dx.doi.org/10.22159/ijpps.2017v9i2.15770

\section{INTRODUCTION}

28-Homocastasterone (28-HC) structurally a keto-isoform is an active plant growth regulator among the brassinosteroid (Bs) family members [1]. 28-homocastasterone and 28-homobrasslinolide (aldoisoform) are actively synthesised in plants by CYP72B1 enzyme and contribute to a wide range of physiological processes during the plant life cycle from seed development to modulation of flowering, senescence, stress response and photomorphogenesis [2].

Humans are exposed to 28-homocastasterone hormones through consumption of plant materials as food and herbal based folk medicine. Assimilation of 28-homocastasterone hormone into tissues induces metabolic changes in animal cells [3]. However, an earlier study in our lab employed with 28-homobrasslinolide and 28homocastasterone an aldo-keto isoform displayed anti-glycemic effect and increased RBC and haemoglobin $(\mathrm{Hb})$ level both in normal and diabetic male adult wistar rats [4]. The haemo cytological effects of 28$\mathrm{HB}$ and 28-HC on mammalian blood cells and bone remain unknown.

Bone marrow are the principal hematopoietic organ and responsible for the production of cellular blood elements and it can be influenced by nutritional, hormonal, physiological, pathological factors and drugs intake [5]. Humans are consuming phyto oxysterol more or less on a regular basis and we assume that it may be influenced haematological status and bone physiology. Earlier studies showed that 28-HC exhibits anti-glycemic activity. Hence it is important to understand 28HC haematopoietic potency in normal and pathological condition [69]. For this purpose, we used normal and STZ-induced diabetic rat model in the present study and evaluated the effect of 28-HC on hematopoiesis and bone histomorphology.

\section{MATERIALS AND METHODS}

\section{Chemicals and reagents}

All chemicals used were of analytical grade and purchased from Sigma-Aldrich, Mo, USA. Staining reagents hematoxylin and eosin were purchased from Himedia, India. 28-HC was courtesy of Dr. V. S. Pori. NCL, Pune, India.

\section{Experimental design}

Male albino wistar rats (Rattus norvegicus) 8-10 w old and weighing about 150-180 gm were purchased from Sri Raghavendra Enterprises, Bengaluru, India. They were housed in plastic cages and given atmospheric temperature $\left(25 \pm 5^{\circ} \mathrm{C}\right)$ and $12 \mathrm{~h} \mathrm{light} /$ dark cycle. Rats were allowed freely access water and standard diet ad libitum during the course of the experiment. Animal use and care were in compliance with that of the CPCSEA regulations and Institutional Animal Ethics Committee (IAEC) guidelines (IAEC/Approval. No.2013-14/01). Rats were divided into four groups of 6 rats in each, Group I: Normal control, Group II: Normal+28-homocastasterone (28-HC 100 $\mu \mathrm{g} / 150 \mathrm{gm}$ bwt), Group III: Diabetic control, Group IV: Diabetic+28-homocastasterone (28-HC $100 \mu \mathrm{g} / 150 \mathrm{gm}$ bwt). Diabetes was induced through a single intra-peritoneal injection of $60 \mathrm{mg} / \mathrm{kg}$ bwt streptozotocin in citrate buffer $(0.1 \mathrm{M}, \mathrm{pH} 4.5)$ to overnight fasted rats. After $48 \mathrm{hr}$, circulating blood glucose level was measured using a glucometer (OneTouch Horizon, Accuva check). Rats exhibiting blood glucose content $>250$ $\mathrm{mg} / \mathrm{dL}$ were considered diabetic. Control groups I and IV received 50\% ethanol alone. Groups II and IV received $666 \mathrm{mg} / \mathrm{kg}$ bwt 28-HC in 50\% ethanol by oral gavage daily for 15 consecutive days.

\section{Blood cell count}

Red blood cells (RBCs), white blood cells (WBCs), granulocytes, monocytes, lymphocytes and platelets were analyzed using fully automated blood cell counter (RC-210 Fully Automatic Blood Cell Counter, Rohan Consortium Pvt. Ltd). Hb level was also determined by the same instrument [10].

\section{Serum electrolytes analysis}

$\mathrm{Na}^{+}, \mathrm{K}^{+}, \mathrm{Cl}+\mathrm{P}$ and $\mathrm{Ca}^{2+}$ were analyzed in rat serum samples using an automated electrolytes analyser as per manufacturer's instruction provided by kit [11].

\section{Serum alkaline phosphatase assay}

The analysis of serum ALP activity was carried out using ALP diagnostic Kit (obtained from Aggape, Karalla, India) protocol adopted as per manufactures guidelines [12]. 


\section{Bone marrow aspiration cytology}

Following euthanasia, the femur bone was removed, and excess muscle and fat were trimmed. The bone is split longitudinally, and marrow was opened. Using a fine brush, a small plug of marrow was gently extracted and smeared onto glass slides and immediately fixed in methanol for $\mathrm{H} / \mathrm{E}$ staining [5]. The stained slide films were examined under camera fitted binocular microscopy (Olympus 100) at $20 \mathrm{x}$ magnifications.

\section{Histomorphology analysis of bone}

The dissected femur bone was fixed in $10 \%$ formaldehyde for $24 \mathrm{~h}$ after removal of the surrounding soft tissues. Decalcification was performed with a $10 \%$ ethylenediamine tetraacetate (EDTA) solution for $5 \mathrm{~d}$. The fixed and decalcified femur bone was embedded in paraffin and sectioned at $5 \mu \mathrm{m}$ using digitalized microtome. Paraffin bone sections were stained with hematoxylin/eosin (H/E stain) and masson trichrome stain [13]. The histomorphology of bone was examined under the binocular microscope (Olympus 100) at 20x and 40x magnification.

\section{Statistical analysis}

Results of the investigations were expressed as mean \pm SD and the data was analysed by one-way ANOVA employing SPSS software 16.0 version. The value of $p<0.05$ was considered significant.

\section{RESULTS}

Rats administered $28-\mathrm{HC}(100 \mu \mathrm{g} / 150 \mathrm{gm}$ bwt $)$ through oral gavage for $15 \mathrm{~d}$ (table 1) showed increased RBCs and $\mathrm{Hb}$ level in treated diabetic group compared to diabetic control group significantly $(\mathrm{p}<0.05)$. RBCs count increased $5.6 \%$ in the treated diabetic group and $2 \%$ in normal treated group. $\mathrm{Hb}$ level increased $5.66 \%$ in the treated diabetic group compared to the untreated diabetic group. On the other hand total WBCs count noted decreased by $33.33 \%$ in normal $28-\mathrm{HC}$ treated rat compared to normal control. In addition, normal 28-HC treated rat platelets count decreased significantly compared to control $(\mathrm{P}<0.05)$.

Table 1: Effect of 28-homocastasterone on blood cells count

\begin{tabular}{|c|c|c|c|c|}
\hline Groups & RBC $10 \times 6 / \mu l$ & Hb g/l & TWBC $10 \times 3 / \mu l$ & Platelets $10 \times 3 / \mu \mathrm{l}$ \\
\hline Control & $7.83 \pm 1.02$ & $15.90 \pm 0.08$ & $09.40 \pm 0.42$ & $266 \pm 14$ \\
\hline Control+28-HC & $7.86 \pm 0.95$ & $16.80 \pm 0.62^{\dagger}$ & $11.50 \pm 0.86^{\dagger}$ & $179 \pm 9^{\dagger}$ \\
\hline Diabetic & $6.42 \pm 0.84$ & $12.60 \pm 0.73$ & $03.50 \pm 0.26$ & $444 \pm 12$ \\
\hline Diabetic $+28-\mathrm{HC}$ & $6.78 \pm 0.72^{*}$ & $14.90 \pm 0.85^{*}$ & $04.90 \pm 0.37 *$ & $334 \pm 16^{*}$ \\
\hline
\end{tabular}

Values are expressed \pm SD. Group $n=6$. ${ }^{\dagger}$ Group Indicates statistical significance against normal control $(\mathrm{p}<0.05)$. ${ }^{*}$ Indicates statistical significance against diabetic control $(\mathrm{p}<0.05)$.

Change in mean corpuscular volume (MCV) (table 2) decreased by $9 \%$ on diabetic treated rat and only by $0.8 \%$ in treated control rat. The diabetic control rat MCV, however, remained elevated $13 \%$ above that of the normal control. In a similar manner, the mean corpuscular hemoglobin (MCH) showed a downward trend in 28$\mathrm{HC}$ treated control and in the treated diabetic rat, the reduction was $8 \%$. In contrast, MCH level showed an increase of $1.9 \%$ on diabetic control rat. The mean corpuscular hemoglobin concentration $(\mathrm{MCHCH})$ was determined as a percentage of the cell content. Similar to the observation noted for $\mathrm{MCH}$, MCHCH in treated control rat decreased $4.8 \%$ in the $15 \mathrm{~d}$ treatment. However, in the diabetic control, the change was $2.5 \%$ above the normal control. In the treated diabetic rat there was $6 \%$ below diabetic control.

Table 2: Effect of 28-homocastasterone on blood cells indices

\begin{tabular}{llll}
\hline Groups & MCVfL & MCH \% & MCHC \% \\
\hline Control & $60.1 \pm 0.53$ & $21.4 \pm 0.62$ & $35.7 \pm 0.35$ \\
Control+28-HC & $59.6 \pm 0.38$ & $20.2 \pm 0.35$ & $34.0 \pm 0.48$ \\
Diabetic & $68.1 \pm 0.64$ & $21.8 \pm 0.5$ & $36.6 \pm 0.38$ \\
Diabetic+28-HC & $62.1 \pm 0.52^{*}$ & $20.0 \pm 0.45$ & $32.3 \pm 0.42$ \\
\hline
\end{tabular}

Values are expressed \pm SD. Group $n=6$. ${ }^{\dagger}$ Group Indicates statistical significance against normal control $(\mathrm{p}<0.05)$. *Indicates statistical significance against diabetic control $(\mathrm{p}<0.05)$.

Table 3: Effect of 28-homocastasterone on platelets indices

\begin{tabular}{llll}
\hline Groups & MPV fL & PDW fL & PCT fL \\
\hline Control & $7.1 \pm 1.20$ & $8.4 \pm 1.21$ & $0.23 \pm 0.05$ \\
Control+28-HC & $6.9 \pm 1.58^{\dagger}$ & $7.9 \pm 1.20^{\dagger}$ & $0.15 \pm 0.08^{\dagger}$ \\
Diabetic & $9.7 \pm 1.25$ & $10.0 \pm 1.39$ & $0.12 \pm 0.06$ \\
Diabetic+28-HC & $7.0 \pm 0.93^{*}$ & $8.7 \pm 1.24^{*}$ & $0.12 \pm 0.08$ \\
\hline
\end{tabular}

Values are expressed \pm SD. Group $n=6$. ${ }^{\dagger}$ Group Indicates statistical significance against normal control $(\mathrm{p}<0.05)$. *Indicates statistical significance against diabetic control $(\mathrm{p}<0.05)$.

Table 4: Effect of 28-homocastasterone on blood electrolytes level

\begin{tabular}{lllll}
\hline Groups & $\mathbf{N a}^{+} \mathbf{m E q} / \mathbf{l}$ & $\mathbf{K}^{+} \mathbf{m E q} / \mathbf{l}$ & $\mathbf{C l} \cdot \mathbf{m E q} / \mathbf{l}$ & $\mathbf{P} \mathbf{m E q} / \mathbf{l}$ \\
\hline Control & $133 \pm 6$ & $9.8 \pm 1.20$ & $96 \pm 4$ & $6.3 \pm 0.24$ \\
Control+28-HC & $120 \pm 4^{\dagger}$ & $7.9 \pm 0.4^{\dagger}$ & $90 \pm 2^{\dagger}$ & $6.0 \pm 0.45^{\dagger}$ \\
Diabetic & $148 \pm 5$ & $12 \pm 0.6$ & $106 \pm 4$ & $7.2 \pm 0.15$ \\
Diabetic+28-HC & $130 \pm 6^{*}$ & $6.0 \pm 0.8^{*}$ & $85 \pm 3^{*}$ & $6.3 \pm 0.18^{*}$ \\
\hline
\end{tabular}

Values are expressed \pm SD. Group $n=6$. ${ }^{\dagger}$ Group Indicates statistical significance against normal control $(\mathrm{p}<0.05)$. *Indicates statistical significance against diabetic control $(\mathrm{p}<0.05)$. 
Table 5: Effect of 28-homocastasterone on serum ALP activity

\begin{tabular}{lll}
\hline Group & ALP IU/l & After treatment \\
\cline { 2 - 3 } & Before treatment & $411 \pm 10.73$ \\
\hline Control & $356 \pm 10.45$ & $487 \pm 5.98 \dagger$ \\
Control+28-HC & $341 \pm 11.05$ & $485 \pm 12.45$ \\
Diabetic & $522 \pm 12.82$ & $582 \pm 11.54^{*}$ \\
Diabetic+28-HC & $517 \pm 11.26$ & \\
\hline
\end{tabular}

Values are expressed \pm SD. Group $n=6$. ${ }^{\dagger}$ Group Indicates statistical significance against normal control $(\mathrm{p}<0.05)$. ${ }^{*}$ Indicates statistical significance against diabetic control $(\mathrm{p}<0.05)$.

In diabetic control rat, there was a significant increase in the serum electrolytes sodium, potassium, and calcium (table 4). Oral administration of 28- $\mathrm{HC}$ reduced the levels of serum electrolytes $\mathrm{Na}^{+}, \mathrm{K}^{+}, \mathrm{Cl}, \mathrm{P}$ and $\mathrm{Ca}^{2+}$ when compared to normal rats. In contrast (table 5) serum ALP activity increased in the 28-HC treated group compared to respective controls.

Bone marrow aspiration examination (fig. 1) normal control bone marrow aspirate showed the normal cellularity and active trilineage hematopoiesis. In 28-HC treated normal rat, moderate cellularity with myeloid suppression and increased immature megakaryocytes and myeloid cells in the bone marrow aspirate were observed. Diabetic control rat, marrow aspirate showed hypocellularity with relative suppression of erythrocytes and myeloid cells. Diabetic 28HC treated rat, cellular with relative myeloid suppression and increase in immature megakaryocytes were observed.

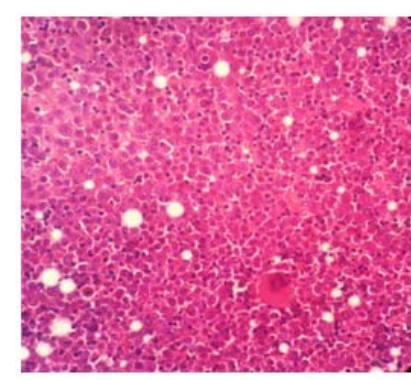

a. Normal Control

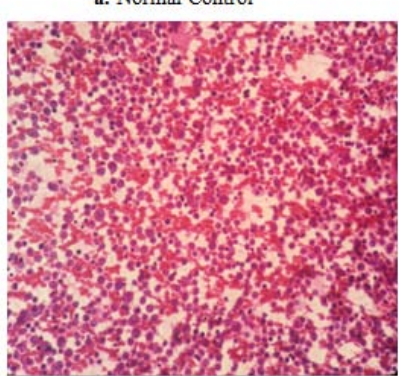

c. Diabetic Control

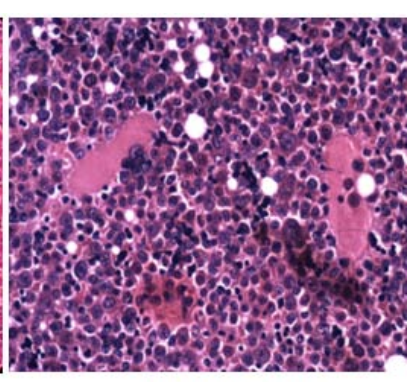

b. Control $+28-\mathrm{HC}$

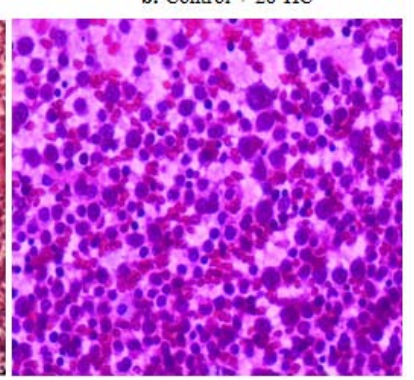

d. Diabetic $+28-\mathrm{HC}$
Fig. 1: Bone marrow aspiration cytology following $15 \mathrm{~d}$ oral administration of $28-\mathrm{HC}$

Fig. 1. Bone marrow aspiration examined at $40 \mathrm{x}$ magnification, a. Normal control: normal cellularity and active trilineage hematopoiesis, b. Control+28-HC treated: Moderate cellularity with myeloid suppression and increase in immature megakaryocytes and immature myeloid cells, c. Diabetic control: hypocellularity with relative suppression of megakaryocytes, $d$. Diabetic $+28-\mathrm{HC}$ treated: cellular marrow with relative myeloid suppression and increase in immature megakaryocytes.

Histologic features were studied in H/E and masson trichrome stained bone tissues of normal and 28-homocastasterone treated rat femur bone were examined. Normal control rat bone marrow biopsy showed normal bone trabeculae with normal marrow elements. 28-HC treated normal (fig. 2 and fig. 3 ) rat bone tissue biopsy showed moderate cellularity with myeloid suppression, increased immature megakaryocytes, immature myeloid cells and trabeculae showed osteoblasts. Diabetic control rat bone tissues showed patchy hypocellularity with relative suppression of megakaryocytes cellular with osteoclasts in the bony trabeculae. Diabetic 28-HC treated rat (fig. 2 and fig. 3 ) bone tissue showed myeloid suppression, increased immature megakaryocytes and bony trabeculae is rimmed by osteoblasts.

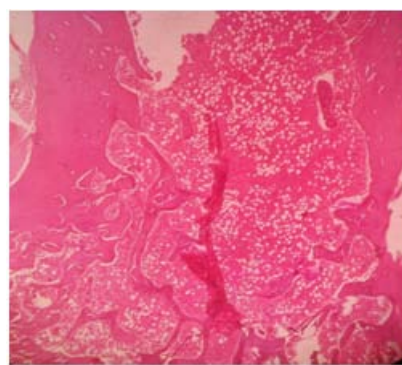

a. Normal Control

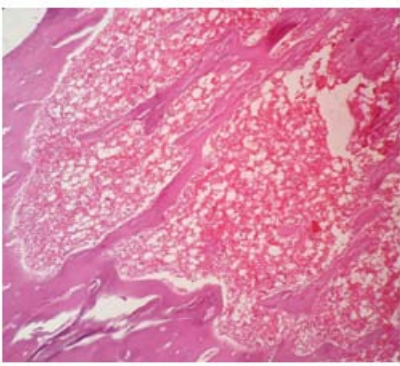

c. Diabetic Control

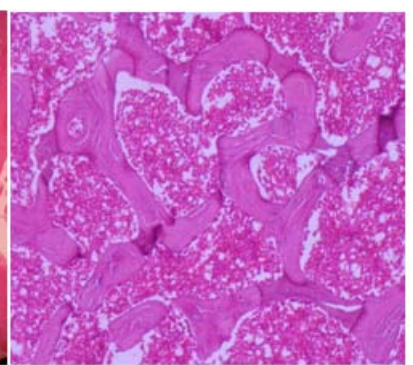

b. Control $+28-\mathrm{HC}$

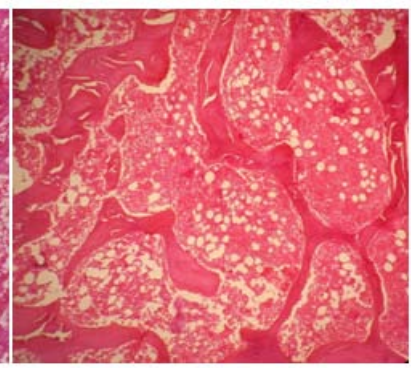

d. Diabetic $+28-\mathrm{HC}$
Fig. 2: Bone histology following $15 \mathrm{~d}$ oral administration of 28-HC

Fig. 2. Bone Histology $\mathrm{H} / \mathrm{E}$ stain section examined at $40 \mathrm{x}$ magnification, a. Normal control: Bone marrow aspirate with normal cellularity and active trilineage hematopoiesis. Bone marrow biopsy shows active trilineage hematopoiesis, b. Control+28-HC treated: Moderate cellularity with myeloid suppression and increase in immature megakaryocytes and immature myeloid cells in both aspirate and bone biopsy, c. Diabetic control: Patchy hypocellularity with relative suppression of megakaryocytes, d. Diabetic $+28-\mathrm{HC}$ treated: cellular marrow with relative myeloid suppression and increase in immature megakaryocytes.

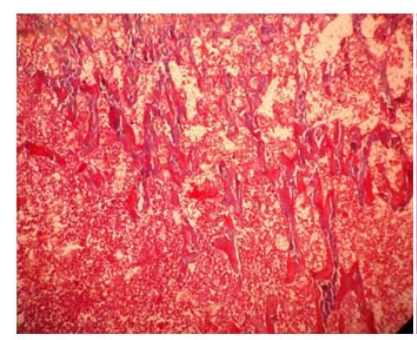

a. Normal Control at $20 \mathrm{x}$

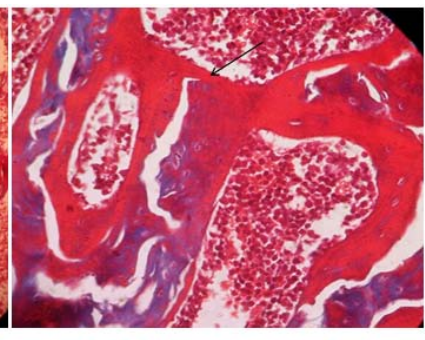

a. Normal Control $40 \mathrm{x}$ 


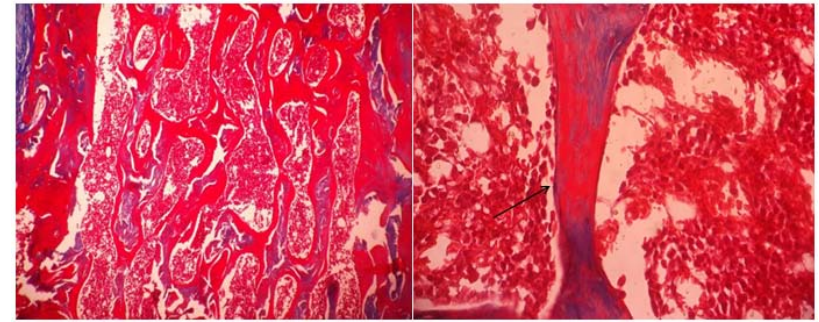

b. Control + 28-HC $20 \mathrm{x}$ b. Control $+28-\mathrm{HC} 40 \mathrm{x}$

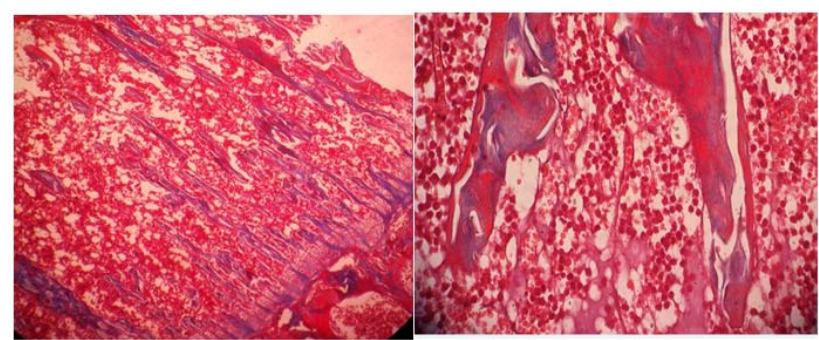

c. Diabetic Control $20 \mathrm{x}$

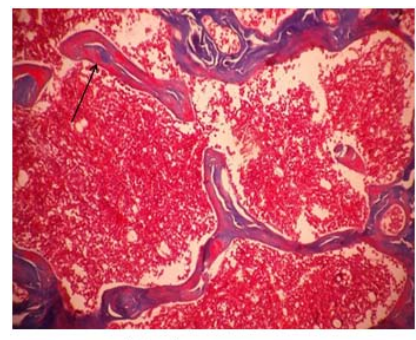

d. Diabetic $+28-\mathrm{HC} 20 \mathrm{x}$ c. Diabetic Control $40 \mathrm{x}$

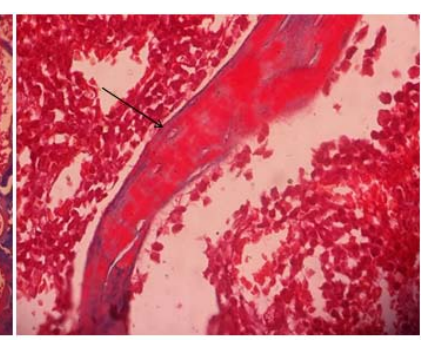

d. Diabetic $+28-\mathrm{HC} 40 \mathrm{x}$
Fig. 3: Bone histology following $15 \mathrm{~d}$ oral administration of 28-HC

Fig. 3. Bone Histology masson trichrome stained section examined at 20x and 40x magnification, a. Normal control: masson trichrome stain is highlighting the bone collagen with normal osteoblastic activity in the bony trabeculae, b. Control+28-HC treated: Increase in the trabecular thickness with more osteoblastic activity, c. Diabetic control: Osteoblastic activity was suppressed, d. Diabetic+28-HC treated: a relative increase in trabecular thickness with increase in osteoblastic activity.

\section{DISCUSSION}

In the present study, the oral fed with $28-\mathrm{HC}$ induces haematological changes on STZ-induced diabetic and normal rats. Thus results clearly shown that normal control group rats that received 28-HC increases in RBC, Hb, and platelets. However, the MCV, MCH, MCHC, PMV, PWD and PCT all exhibited decreased by $15^{\text {th }}$ day for $100 \mu \mathrm{g}$ dose of 28-HC administered. These observations suggest that 28-HC may capable of regulating cell proliferation and differentiation in the marrow and hence the cells released into the circulation could perhaps remain premature, which are morphologically and functionally abnormal $[14,15]$.

28-HC administered to STZ-induced diabetic rat caused a returned diabetes-induced bone tissue morphological changes along with increased bone marrow cellularity compared to diabetic control, which suggested 28-HC induced the hematopoietic effect. On the other hand bone marrow aspiration cytology examination secured the increase in proerthrocytic and promegakaryocyte cell lineages increased and other side sever downward trend in lymphocytic cell lineages was observed. This suggested that 28-HC specifically induces megakaryocyte/erythrocyte progenitor cells and deviating common lymphoid progenitor cell linage. Thus pointed out that 28-HC influenced on blood cells formation, that of reflected from peripheral blood circulation was analyses confirming in this effect of 28-HC [15].

Histologic features of normal and 28-HC treated rat femur bone were examined, 28-HC treated normal rat osteoblasts in bone biopsy and diabetic control rat bone tissues showed osteoclasts in the bony trabeculae. In 28-HC treated diabetic rat bony trabeculae is rimmed by osteoblasts (fig. 2 and fig. 3) It is clear that 28-HC influences bone osteoblast/osteoclast in a diabetic subject. In addition, serum ALP activity increased (table 5) in the 28-HC treated group compared to respective controls. Marker of the osteoblast/osteoclast in serum such as ALP is further was also supportive in this finding [17].

Increased glucose oxidation in the presence of transition metals has been shown to produce membrane damage by membrane lipid peroxidation and protein glycation [13]. This could be the reason for the altered electrolyte balance in diabetic rat, which resulted in the elevated serum sodium, potassium and calcium in STZ-induced diabetic rats. However, administration of 28-HC reduced the glucose level and restored tissue electrolytes and this can be the possible cause for the reduction of the serum electrolytes levels [16].

\section{CONCLUSION}

The present study confirms that the plant ketosteroid 28homocastasterone exhibits the hematopoietic effect. When administered, this compound improved platelet indices in diabetic rat blood and increased $\mathrm{RBC}, \mathrm{Hb}$ and $\mathrm{WBC}$ levels significantly. Histology study in bone tissues showed that increased osteoblastic activity and improved bone histomorphology in 28-HC treated rat. The molecular mechanism underlying alteration in marrow cells and bone histology changes need further study.

\section{ACKNOWLEDGEMENT}

The authors acknowledge Dr. V. S. Pori, Scientist E, National Chemical Laboratory (CSIR), Pune, India, for the gift of 28-homocastasterone used in this study. Author V. Athithan, gratefully acknowledges the financial support received through Research Fellowship from University Grants Commission (UGC), New Delhi, India. Authors acknowledged Department of Pathology, JIPMER, Pondicherry, India for provided histopathology facility to carry out present study.

\section{CONFLICT OF INTERESTS}

Authors declare no conflict of interest

\section{REFERENCES}

1. Takatsuto S, Ikekawa N, Morishita T, Abe H. Structure-activity relationship of brassinosteroids with respect to the A/B-ring functional groups. Chem Pharm Bull 1987;35:211-6.

2. Sasse JM. Physiological actions of brassinosteroids: an update. J Plant Growth Regul 2003;22:276-88.

3. Muthuraman P, Srikumar K. A comparative study on the effect of homo brassinolide and gibberellic acid on lipid peroxidation and antioxidant status in normal and diabetic rats. J Enzyme Inhib Med Chem 2009;24:1122-7.

4. Muthuraman P, Srikumar K. Induction of hexokinase I expression in normal and diabetic rats by a brassinosteroid isoform. Eur J Pharm Sci 2010;41:1-9.

5. Travlos GS. Normal structure, function, and histology of the bone marrow. Toxicol Pathol 2006;34:548-65.

6. Premalatha R, Jubendradass R, Rani SJ, Srikumar K, Mathur PP. A phytol oxysterol, 28-homobrassinolide modulates rat testicular steroidogenesis in normal and diabetic rats. Reprod Sci 2012;20:589-96.

7. Bucala R, Tracey KJ, Cerami A. Advanced glycosylation products quench nitric oxide and mediate defective endotheliumdependent vasodilatation in experimental diabetes. JCI Insight 1991;87:432-8.

8. Jindal S, Gupta S, Gupta R, Kakkar A, Singh HV, Gupta K, et al. Platelet indices in diabetes mellitus: indicators of diabetic microvascular complications. Hematology 2011;16:86-9.

9. Andrade-Cetto A, Revilla-Monsalve C, Wiedenfeld $\mathrm{H}$. Hypoglycemic effect of Tournefortiahirsutissima $L$ on $n$ streptozotocin diabetic rats. J Ethnopharmacol 2007;112:96-100.

10. Maciel TE, Comar SR, Beltrame MP. Performance evaluation of the Sysmex® XE-2100D automated hematology analyzer. J Bras Patol Med Lab 2014;50:26-35.

11. Wymenga L FA, Boomsma JHB, Groenier K, Piers DA, Mensink HJA. Routine bone scans in patients with prostate cancer 
related to serum prostate-specific antigen and alkaline phosphatase. BJU Int 2001;88:226-30.

12. Alers JC, Krijtenburg PJ, Vissers KJ, Van Dekken H. Effect of bone decalcification procedures on DNA in situ hybridization and comparative genomic hybridization: EDTA is highly preferable to a routinely used acid decalcifier. J Histochem Cytochem 1999;47:703-10.

13. Gayathri M, Kannabiran K. Hypoglycemic activity of Hemidesmusindicus R. Br. on streptozotocin-induced diabetic rats. Int J Diabetes Dev Ctries 2008;28:6-10.

14. Young NS, Maciejewski J. The pathophysiology of acquired aplastic anemia. N Engl J Med 1997;336:1365-72.

15. Athithan V, Premalatha R, Mukherjee V, Mani N, Srikumar K. Homocastasterone: a novel plant ketosteroid inducing haematological changes in normal and diabetic male Rat. Int J Pharm Pharm Sci 2015;7:125-8.

16. Gayathri M, Kannabiran K. Anti-diabetic and ameliorative potential of Ficusbengalensis bark extract in streptozotocin are induced diabetic rats. Indian I Clin Biochem 2008;23:394-400.

17. Bonnelye E, Chabadel A, Saltel F, Jurdic P. Dual effect of strontium ranelate: stimulation of osteoblast differentiation and inhibition of osteoclast formation and resorption in vitro. Bone 2008;42:129-38.

\section{How to cite this article}

- Velan Athithan, Kotteazeth Srikumar. Phytohormone induced changes on bone histology in normal and diabetic male rat. Int Pharm Pharm Sci 2017;9(2):287-291. 